\title{
Perfluoroalkyl acids in dust on residential indoor/outdoor window glass in Chinese cities: occurrence, composition and toddler exposure
}

Zhen Zhao ( $\sim$ zzhao@shou.edu.cn )

Shanghai Ocean University https://orcid.org/0000-0003-2029-4520

Linxia Yue

Peking University Shenzhen Graduate School

Hongqin Qiao

Henan Normal University

Yinong Li

Nankai University

Xianghui Cheng

Henan Normal University

Xia Hua

Nankai University

Tian Lin

Shanghai Ocean University

Qilu Li

Henan Normal University

Hongwen Sun

Nankai University

\section{Research Article}

Keywords: PFAA, dust, window glasses, toddler exposure

Posted Date: May 27th, 2021

DOl: https://doi.org/10.21203/rs.3.rs-209928/v1

License: (c) (i) This work is licensed under a Creative Commons Attribution 4.0 International License. Read Full License

Version of Record: A version of this preprint was published at Environmental Science and Pollution Research on October 1st, 2021. See the published version at https://doi.org/10.1007/s11356-021-16653-w. 


\section{Abstract}

The dust on indoor and outdoor surfaces of the window glasses were collected using sterile cotton balls in 11 cities. Twenty-nine perfluoroalkyl acids (PFAAs) were quantified to investigate concentration, composition and toddlers' exposure. The concentrations of $\sum$ PFAA ranged from no detection (nd) to $43 \mathrm{ng} / \mathrm{m}^{2}$ (mean 8.9 $\pm 10 \mathrm{ng} / \mathrm{m}^{2}$ ). Perfluorobutanoic acid (PFBA) was detected in $78 \%$ samples, and accounted for $55 \% \pm 21 \%$ of \PFAA concentrations. 6:2 Fluorotelomer sulfonic acid (6:2 FTSA) and hexafluoropropylene oxide dimer acid (HFPO-DA) were detected in more than 50\% samples indicating the use of alternatives. Fluorotelomer carboxylic acid (FTCA) and fluorotelomer unsaturated acid (FTUCA) were found in the dust, implying the degradation of precursors. The highest concentration of $\sum$ PFAA $\left(43 \mathrm{ng} / \mathrm{m}^{2}\right)$ was found in outdoor dust from Xinzhou, Shanxi Province, which is famous for its coal resources. Higher $\sum$ PFAA concentrations were found in indoor dust than outdoor in 6 paired samples ( 3 from Feb. 14 and 3 from Feb. 21). In Tianjin and Handan, the concentrations of $\sum$ PFAA from outdoor surfaces were higher in sampling campaign I (SC I, Feb. 21) than in sampling campaign II (SC II, Feb. 14), implying intensive outdoor release. The exposure of 2 year-old toddlers to PFAA via hand-to-mouth ingestion and dermal absorption was estimated; the mean values of intake were 2.1 and $1.5 \mathrm{pg} / \mathrm{kg}$ body weight, respectively, assuming an exposure time of 1 hour.

\section{Introduction}

Perfluoroalkyl acids (PFAA) are artificial chemicals that possess characteristics of thermal resistance, physical and chemical stability, and repellency of water and oil (Giesy and Kannan 2002, OECD 2018). PFAA have been widely used for more than 60 years in manufacturing industries and commercial products, such as metal plating, fluoropolymer manufacturing, aqueous firefighting foams (AFFFs), textile, paper, and water repellent items. Some legacy PFAA, for instance, perfluorooctane sulfonate acid (PFOS) and perfluorooctanoic acid (PFOA), are persistent and bioaccumulative and have potential toxicity to biota and humans (Lindstrom et al., 2011). In 2000, the manufacturers began to phase out the production of $\mathrm{C}_{8}$ analogues (Zhang et al., 2020a). In 2009, PFOS and related compounds were listed in Annex B of the Stockholm Convention on persistent organic pollutants (POPs), and in 2019, PFOA was added to Annex $A(U N E P)$. Since the worldwide restriction, alternatives ( $C_{4}$ PFAA for example) have been used, which have been found in the air, water, sediments and human body globally (Heydebreck et al., 2015, Bao et al., 2017, Guo et al., 2018). The $C_{4}$ PFAA, such as perfluorobutanoic acid (PFBA) and perfluorobutane sulfonate acid (PFBS), have been reported low threats to health and migrate easily due to their short carbon chains, and they have been reported in air, surface water, and groundwater in recent studies (Yu et al., 2018b, Bao et al., 2019, Gao et al., 2020). Fluorotelomer sulfonate acids (FTSAs), especially, 6:2 FTSA, have been used as substitutes for PFOS in some AFFF and other commercial products, and they have been found in airports and other firefighting training locations (Dauchy et al., 2019, Feng et al., 2020). Hexafluoropropylene oxide dimer acid (HFPO-DA) is an alternative to PFOA in industrial activities, and high concentrations have been found in Chinese fluorochemical industrial parks (Heydebreck et al., 2015, Heydebreck et al., 2016).

Dust is considered to be representative for monitoring some POPs, and legacy and novel PFAA have been reported in the dust of indoor and outdoor locations worldwide (Besis et al., 2019). PFOA and PFOS are the predominate compounds reported in many previous studies, with concentrations up to hundreds of 
nanogram per gram (Fang et al., 2019a, Zheng et al., 2020). Alternative compounds have been detected in indoor dust at lower concentrations than PFOA and PFOS (de la Torre et al., 2019, Zhang et al., 2020a). Indoor dust in household may reflect the consumption of domestic products, whereas outdoor dust may be influenced by industrial activities (Su et al., 2016). PFAA in dust are strongly related to the human exposure through ingestion and dermal uptake (Cequier et al., 2014, de la Torre et al., 2019). For children, ingestion of settled dust is comparable to dietary intake, and adverse effects due to the PFAA exposure have been identified (Egeghy and Lorber 2011, Braun 2017, Rappazzo et al., 2017).

Vacuum cleaners (Jogsten et al., 2012, Eriksson and Karrman 2015, Zheng et al., 2020), air conditioners (Besis et al., 2019), and precleaned brushes (Su et al., 2016, Zhang et al., 2020a) have been used to collected dust settled on floors, carpets, and furniture in households, classrooms, offices and cars, and the road outdoors. Wipes such as sterile gauze pad soaked in isopropyl alcohol are conventionally used to investigate organic pollutants, including flame-retardants (FRs), chlorinated paraffins (CPs), and organophosphate esters (OPEs) on household and office surfaces (Watkins et al., 2013, Liu et al., 2018, Hammel et al., 2020, Yuan et al., 2020). Poothong et al. (2020) used the same method to collect poly- and perfluoroalkyl substances (PFAS) from hands to evaluate dermal exposure (Poothong et al., 2020). Sterile cotton balls have been used to study polycyclic aromatic hydrocarbons (PAHs) and microencapsulated cyfluthrin (Stout and Leidy 2000, Fleming and Ashley 2013), and could be similarly useful to collect PFAA in dust. Horizontal surfaces have generally been studied more than vertical surfaces. Glass commonly used in structures to allow sunlight inside, reduce weight or ornament buildings. Dust on window glass does not accumulated in thick layers, but windows are not cleaned as often as horizontal surfaces such as floors. Moreover, these heterogeneous conditions may be beneficial for the degradation of PFAA precursors, especially due to sunlight conditions (Kutsuna et al., 2006, Taniyasu et al., 2013, Sun et al., 2015).

The aims of this study were to investigate the levels and composition of novel and legacy PFAA in dust on window glass, to reveal the distribution of PFAA in dust in different Chinese cities, and to estimate toddlers' hand-to-mouth exposure to PFAA.

\section{Materials And Methods}

\subsection{Chemicals and standards}

Twenty-nine PFAAs were targeted including perfluoroalkyl carboxylic acids (PFCAs) with carbon chain lengths of 4-12, i.e., PFBA, perfluropentanoic acid (PFPeA), perfluorohexanoic acid (PFHxA), perfluoroheptanoic acid (PFHpA), PFOA, perfluorononanoic acid (PFNA), perfluorodecanoic acid (PFDA), perfluoroundecanoate acid (PFUnA), and perfluorododecanoic acid (PFDoDA), perfluoroalkane sulfonic acids (PFSAs) with carbon chain lengths of 4, 6 and 8, i.e., PFBS, perfluorohexanesulfonate acid (PFHxS), and PFOS, 6:2 and 8:2 fluorotelomer unsaturated carboxylic acids (FTUCAs), 3:3, 5:3, 6:2, 8:2 and 7:3 fluorotelomer carboxylic acids (FTCAs), 4:2, 6:2, 8:2 and 10:2 fluorotelomer sulfonic acids (FTSAs), 6:2 and 8:2 chlorinated polyfluorinated ether sulfonic acid (6:2 and 8:2 Cl-PFESA), ammonium 4,8-dioxa-3Hperfluorononanoate (ADONA), HFPO-DA and perfluoro-4-ethylcyclohexanesulfonate (PFECHS). Thirteen mass labeled compounds were used as internal standards (IS), i.e., ${ }^{13} \mathrm{C}_{4}-\mathrm{PFBA},{ }^{13} \mathrm{C}_{3}-\mathrm{PFPeA},{ }^{13} \mathrm{C}_{2}$-PFHxA, 
${ }^{13} \mathrm{C}_{4}$-PFHpA, ${ }^{13} \mathrm{C}_{4}$-PFOA, ${ }^{13} \mathrm{C}_{2}$-PFNA, ${ }^{13} \mathrm{C}_{2}$-PFDA, ${ }^{13} \mathrm{C}_{2}$-PFUnDA, ${ }^{13} \mathrm{C}_{2}$-PFDoA, ${ }^{18} \mathrm{O}_{2}-\mathrm{PFHxS},{ }^{13} \mathrm{C}_{4}-\mathrm{PFOS},{ }^{13} \mathrm{C}_{2}-6: 2$ FTSA, and ${ }^{13} \mathrm{C}_{2}-8: 2$ FTSA. All the standards were purchased from Wellington Laboratories Inc. (Ontario, Canada). Chromatographic grade methanol and ammonium hydroxide (v/v, 25\%) were purchased from Merck company (Darmstadt, Germany). The Envi-Carb cartridge ( $3 \mathrm{~mL}, 250 \mathrm{mg}$ ) was purchased from Supelco (Bellefonte, USA). Nylon member filters (13 mm, $0.22 \mu \mathrm{m}$ ) were purchased from Pall Co. (New York, USA).

\subsection{Sampling campaign}

February 16, 2018 was the Spring Festival of China, and before the festival, all the Chinese families would clean their house as a tradition more than 4000 years. This might be an efficient way to eliminate the potential healthy threaten from indoor dust. We collected the dust on the window glasses inside and outside of 11 flats on February 14 (Sampling Campaign I, SC I) and February 21, 2018 (Sampling Campaign II, SC II). The sampling sites were located in cities of China from north to south: Harbin (Heilongjiang Province), Ordos (Inner Mongolia), Tianjin, Xinzhou (Shanxi Province), Handan and Shijiazhuang (Hebei Province), Sanmenxia and Nanyang (Henan Province), Jiujiang (Jiangxi Province), Sanya (Hainan Province) and Hong Kong. In Shjiazhuang and Sanya, the dust on the outside glass surface was not collected for safety. The kitchen and bathroom windows were not considered. The details of the sampling information were presented in Table S2. The medical sterilizing cotton ball $(0.5 \mathrm{~g})$ was used to collect the dust on the window glasses. The soft and fluffy cotton balls were more effective to collect and keep the dust than gauze or brush. Methanol or other organic solvent was not used when cleaning the glasses, and bulk film was not collected (Diamond et al., 2000). The areas for cleaning ranged from 4 to $7 \mathrm{~m}^{2}$ (for Hongkong $0.6 \mathrm{~m}^{2}$ ). Dust in the $2 \mathrm{~cm}$ range from the window frame were not collected. The numbers of the balls were fixed in each city. Cotton balls with dust were wrapped in aluminum foil, then sealed in polyethylene bags, and stored at $-20^{\circ} \mathrm{C}$ before treatment in laboratory.

\subsection{Sample preparation and instrumental analysis}

The extraction method was referred to the treatment of air filters with some modification. Cotton balls with dust were extracted in polypropylene tube by ultrasound equipment. Before extraction, 5 ng IS mixture was

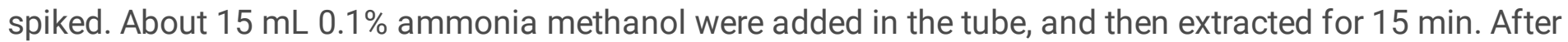
being centrifuged at a speed of $3500 \mathrm{r} / \mathrm{min}$ for $10 \mathrm{~min}$, the superficial liquid was collected. Cotton balls with dust were extracted twice. All extract was collected together, and then concentrated to less than $0.5 \mathrm{~mL}$ under a gentle stream of high purity nitrogen. Envi-carb cartridges and nylon member filters were used to remove the impurity. The final volume of each sample was reduced to $200 \mu \mathrm{L}$.

The instrument analysis employed Agilent 1290 series liquid chromatograph interfaced with an Agilent 6460 triple quadrupole mass spectrometer (HPLC-MS/MS, Agilent Technologies, USA). The detailed information of instrument analysis could be found in previous studies (Fang et al., 2018, Zhao et al., 2020).

\subsection{Equations for uptake exposure}

According the questionnaire, toddlers played near the bay or floor-to-ceiling windows to get more sunlight under the safety supervision. The uptakes via dust ingestion and dermal absorption for toddlers were 
calculated considering their touch on the window glasses. The exposure time (ET) was set as 1 hour. The equations were showed below referring previous studies (COPCC 2003, Liu et al., 2018).

$$
\begin{gathered}
\text { Dust ingestion }=\frac{C_{s} \times F T S S 1 \times S A 1 \times F \times T E \times E T \times 1000}{B W} \\
\text { Dermal adsorption }=\frac{C_{s} \times F T S S 2 \times S A 2 \times A B S \times E T \times 1000}{B W}
\end{gathered}
$$

Cs: PFAA concentration in dust on the inside widow glasses $\left(\mathrm{ng} / \mathrm{m}^{2}\right)$

BW: body weight $(\mathrm{kg})=12 \mathrm{~kg}$ for 2 years old child (NHC 2009)

FTSS1: transfer factor (unitless) $=50 \%($ COPCC 2003)

SA1: skin area contacted in each hand-to-mouth event $\left(\mathrm{m}^{2} /\right.$ event $)=0.0015 \mathrm{~m}^{2}$ for 2 year-old child (COPCC 2003)

F: number of hand-to-mouth events per day (times/h) $=9.5$ times/h for $1-6$ year-old child (COPCC 2003)

TE: transfer efficiency in hand-to-mouth event (\%) = 50\% (COPCC 2003)

ET: exposure time (hours) $=1$ hour

FTSS2: transfer factor (unitless) $=25 \%($ COPCC 2003)

SA2: exposed skin area $\left(\mathrm{m}^{2}\right)=0.0104 \mathrm{~m}^{2}$ for 2 year-old child's palms (Wang et al., 2011)

ABS: absorption factor (unitless) $=48 \%$ for PFAA (Franko et al., 2012)

\subsection{Quality assurance and quality control}

To quantify the background of cotton balls, ten balls were picked at random and extracted as real samples. During sampling, one field blank sample was prepared at each site on each day, and the ball number was consistent to the real sample. The blank samples did not contact the window glasses. PFBA, PFHpA and PFHxA could be detected in blank samples possibly due to the background of the sampling materials. All the tools, i.e., stainless steel tweezers, which could contact the samples were precleaned by ethanol three times. Glass material was avoided through the entire treatment processes to prevent the adsorption (Sorengard et al., 2020). The signal-to-noise ratio of 3 determines the instrument quantification limit (IQL). The method quantification limit (MQL) was defined using a signal-to-noise ratio of 10 for compounds with concentrations below the IQLs in blank samples. For PFBA, PFHpA and PFHxA, the MQLs were calculated as 3 times the standard deviation plus the mean value in the blanks. Table S3 lists the IQL and MQL of each compound. The concentrations below the MQLs were expressed as 'not detected (nd)'. The calibration gradient of the standard curve is $0,0.5,1,2,5,10,20,50,100$, and $200 \mu \mathrm{g} / \mathrm{L}$. The linear correlation coefficients of the individual calibration curves were all greater than 0.991 . The recoveries of IS ranged from 
$58 \% \pm 21 \%\left({ }^{13} \mathrm{C}_{4}-\mathrm{PFBA}\right)$ to $95 \% \pm 7 \%\left({ }^{13} \mathrm{C}_{4}\right.$-PFNA $)$. The concentrations were corrected by average levels of blanks.

\subsection{Statistical analysis}

Spearman relationship was tested for individual compound to examine the associations. For the concentrations below the MQL, the MQL/ $\sqrt{2}$ were assigned. Statistical analysis was performed using SPSS statistics 24 (Spss INC IBM USA).

\section{Results And Discussion}

\subsection{Concentrations and compositions of PFAA}

Twenty-two PFAA were detected in 40 samples of dust from glass, with $\sum$ PFAA concentrations ranging from nd to $43 \mathrm{ng} / \mathrm{m}^{2}$. The three most frequently detected compounds were PFDA ( $45 \%$ in indoor and $35 \%$ in outdoor samples), PFBA (45\% indoor and $33 \%$ outdoor) and PFNA ( $45 \%$ indoor and $35 \%$ outdoor). The detection frequencies of PFOA ( $20 \%$ indoor and $23 \%$ outdoor) and PFOS ( $5 \%$ for both indoor and outdoor) were lower than those of short-chained $(\mathrm{C}<8)$ substitutes, i.e., PFBA ( $45 \%$ indoor and $32 \%$ outdoor) and PFBS (35\% indoor and $28 \%$ outdoor). New alternatives, i.e., HFPO-DA and 6:2 FTSA, were detected in 53\% (30\% indoor and $23 \%$ outdoor) and $68 \%$ ( $40 \%$ indoor and $28 \%$ outdoor) of samples, respectively, levels that were similar to those of $\mathrm{C}_{4}$ substitutes. PFECHS and ADONA had low detection frequency (8\%). 6:2 and 8:2 Cl-PFESA were not detected $(<M Q L)$ in any samples.

The concentrations and compositions of the PFAA were showed in Table 1 and Fig. 1. The predominant compound was PFBA on both indoor and outdoor surface with concentrations ranging from 0.57 to $25 \mathrm{ng} / \mathrm{m}^{2}$ (average of $5.8 \mathrm{ng} / \mathrm{m}^{2}$ in $78 \%$ samples), indicating the replacement of $\mathrm{C}_{8}$ legacy compounds by short-chained ones. Zheng et al. (2020) reported that concentrations of PFBA were higher than those of other PFCA in settled dust in the USA, which was consistent with the present study (Zheng et al., 2020). In China, PFBA was identified as the major compound in $\mathrm{PM}_{10}$ collected from Beijing and Jinzhou, and high concentrations of about $100 \mathrm{pg} / \mathrm{m}^{3}$ accounting for more than $20 \%$ of $\sum_{17}$ PFAA concentrations were reported in Tianjin and Yantai (Yu et al., 2018a). The average concentration of 6:2 FTSA was $1.4 \mathrm{ng} / \mathrm{m}^{2}$ in $58 \%$ of samples, with the highest concentration at $16 \mathrm{ng} / \mathrm{m}^{2} .6: 2 \mathrm{FTSA}$ has been widely detected in water and sediments due to its use as a substitute for PFOS. Zheng et al. (2020) reported high proportions of 6:2 FTSA and 8:2 FTSA in indoor dust from childcare facilities in the USA, possibly released from carpets, paints, waxes, polishes, and floor cleaners, implying that regular cleaning may increase indoor exposure (Herzke et al., 2012, Field and Seow 2017, Zheng et al., 2020). An alternative to PFOA, HFPO-DA showed similar average concentration $\left(1.6 \mathrm{ng} / \mathrm{m}^{2}\right)$ to that of PFOA $\left(1.1 \mathrm{ng} / \mathrm{m}^{2}\right)$ in $38 \%$ samples. PFECHS was detected in $18 \%$ of samples (Table S4-1 and S4-2), with the highest concentrations of up to $9.2 \mathrm{ng} / \mathrm{m}^{2}$ implying the release from hydraulic fluids (Wang et al., 2016). The average concentrations of PFNA in 70\% of samples and PFDA in $80 \%$ of samples were 1.0 and $0.18 \mathrm{ng} / \mathrm{m}^{2}$, respectively. Long-chained PFAAs (C >8) have stronger affinity to particles/dust than do shorter ones, which may explain the high detection frequencies (Higgins and Luthy 2006). Photodegradation may also occur on the window glass. Young et al. (2007) 
investigated the composition of PFAA in Arctic snow and provided some fingerprint ratios to identify the degradation from fluorotelomer alcohols $(\mathrm{FTOH})$, which were the major precursors of PFAA in China (Young et al., 2007, Li et al., 2011). A PFOA/PFNA ratio of $1.5 \pm 0.8$ indicated degradation of 8:2 FTOH; four samples presented PFOA/PFNA ratios in this range. 10:2 FTOH could degrade to PFDA and PFUnDA with a fingerprint ratio of $0.9 \pm 0.8$; eight samples presented such ratios. Moreover, occurrence of the intermediates FTCAs and FTUCAs also indicated precursor degradation (Dinglasan et al., 2004, Ellis et al., 2004, D'Eon et al., 2006). 
Table 1

The concentrations of individual compounds with frequency higher than $50 \%$ and $\sum$ PFAA $\left(\mathrm{ng} / \mathrm{m}^{2}\right)$

\begin{tabular}{|c|c|c|c|c|c|c|c|c|c|}
\hline City & $\begin{array}{l}\text { Sample } \\
\text { label }\end{array}$ & PFBA & PFNA & PFDA & PFUnDA & PFBS & $\begin{array}{l}6: 2 \\
\text { FTSA }\end{array}$ & $\begin{array}{l}\text { HFPO- } \\
\text { DA }\end{array}$ & $\sum$ PFAA \\
\hline & $\begin{array}{l}\text { Detection } \\
\text { frequency }\end{array}$ & $78 \%$ & $70 \%$ & $80 \%$ & $53 \%$ & $58 \%$ & $58 \%$ & $53 \%$ & \\
\hline \multirow[t]{4}{*}{$\begin{array}{l}\text { Harbin, } \\
\text { Heilongjiang }\end{array}$} & $\begin{array}{l}\text { I-HRB- } \\
0214\end{array}$ & 1.9 & 0.16 & 0.14 & 0.02 & 0.01 & 0.16 & 0.50 & 3.2 \\
\hline & $\begin{array}{l}\text { I-HRB- } \\
0221\end{array}$ & 1.0 & 0.16 & 0.17 & 0.04 & 0.02 & 0.19 & nd & 2.1 \\
\hline & $\begin{array}{l}\text { O-HRB- } \\
0214\end{array}$ & 0.94 & nd & 0.15 & nd & nd & nd & 1.87 & 3.7 \\
\hline & $\begin{array}{l}\text { O-HRB- } \\
0221\end{array}$ & 2.3 & 0.13 & 0.14 & 0.01 & nd & nd & 1.11 & 4.3 \\
\hline \multirow{4}{*}{$\begin{array}{l}\text { Ordos, } \\
\text { Inner } \\
\text { Mongolia } \\
\text { Municipality }\end{array}$} & $\begin{array}{l}\text { I-ORDS- } \\
0214\end{array}$ & 1.2 & 0.10 & nd & nd & 0.02 & nd & nd & 1.3 \\
\hline & $\begin{array}{l}\text { I-ORD- } \\
0221\end{array}$ & 0.85 & nd & nd & nd & nd & nd & 0.42 & 1.3 \\
\hline & $\begin{array}{l}\text { O-ORDS- } \\
0214\end{array}$ & nd & nd & nd & nd & nd & 15.68 & nd & 28 \\
\hline & $\begin{array}{l}\text { O-ORDS- } \\
0221\end{array}$ & nd & nd & nd & nd & 0.03 & nd & 0.26 & 0.47 \\
\hline \multirow[t]{4}{*}{ Tianjin } & I-TJ-0214 & 3.8 & 0.75 & 0.11 & nd & 0.11 & 0.13 & nd & 6.4 \\
\hline & I-TJ-0221 & 0.69 & 4.8 & 0.13 & 0.03 & 0.04 & nd & nd & 7.1 \\
\hline & $\begin{array}{l}\text { O-TJ- } \\
0214\end{array}$ & 2.3 & 0.08 & 0.05 & nd & 0.05 & 0.10 & nd & 2.7 \\
\hline & $\begin{array}{l}\text { O-TJ- } \\
0221\end{array}$ & 5.8 & 2.0 & 0.05 & 0.02 & 0.07 & 0.10 & 2.0 & 13 \\
\hline \multirow{4}{*}{$\begin{array}{l}\text { XinZhou, } \\
\text { Shanxi }\end{array}$} & I-XZ-0214 & 3.4 & 0.25 & 0.02 & 0.02 & 0.04 & 0.28 & 4.3 & 11 \\
\hline & I-XZ-0221 & 3.4 & 0.24 & 0.02 & nd & nd & 0.33 & 2.9 & 7.7 \\
\hline & $\begin{array}{l}O-X Z- \\
0214\end{array}$ & 24 & 2.9 & 0.32 & 0.03 & 0.16 & 3.0 & 8.6 & 43 \\
\hline & $\begin{array}{l}0-X Z- \\
0221\end{array}$ & 2.6 & 0.32 & nd & nd & 0.04 & 0.24 & 0.33 & 3.6 \\
\hline Handan, & I-HD-0214 & 5.6 & 0.80 & 0.13 & 0.04 & 0.06 & 0.47 & 3.5 & 15 \\
\hline Hebei & I-HD-0221 & 2.3 & 0.15 & 0.05 & 0.02 & nd & 0.19 & 0.73 & 3.4 \\
\hline
\end{tabular}




\begin{tabular}{|c|c|c|c|c|c|c|c|c|c|}
\hline City & $\begin{array}{l}\text { Sample } \\
\text { label }\end{array}$ & PFBA & PFNA & PFDA & PFUnDA & PFBS & $\begin{array}{l}6: 2 \\
\text { FTSA }\end{array}$ & $\begin{array}{l}\text { HFPO- } \\
\text { DA }\end{array}$ & $\sum$ PFAA \\
\hline & $\begin{array}{l}\text { O-HD- } \\
0214\end{array}$ & 1.2 & nd & 0.02 & nd & nd & 0.23 & nd & 1.5 \\
\hline & $\begin{array}{l}\text { O-HD- } \\
0221\end{array}$ & 0.96 & 0.13 & 0.13 & 0.01 & 0.09 & nd & 0.53 & 4.7 \\
\hline \multirow[t]{4}{*}{$\begin{array}{l}\text { Sanmenxia, } \\
\text { Henan }\end{array}$} & $\begin{array}{l}\text { I-SMX- } \\
0214\end{array}$ & 25 & 1.9 & 0.27 & 0.01 & 0.13 & 1.4 & 1.4 & 33 \\
\hline & $\begin{array}{l}\text { I-SMX- } \\
0221\end{array}$ & 3.4 & 1.1 & 0.23 & 0.02 & 0.04 & 0.40 & 0.52 & 6.3 \\
\hline & $\begin{array}{l}\text { O-SMX- } \\
0214\end{array}$ & 22 & 2.0 & 0.26 & 0.04 & 0.19 & 1.1 & nd & 28 \\
\hline & $\begin{array}{l}\text { O-SMX- } \\
0221\end{array}$ & 3.7 & 0.38 & 0.13 & 0.02 & 0.02 & 0.87 & nd & 5.5 \\
\hline \multirow{4}{*}{$\begin{array}{l}\text { Nanyang, } \\
\text { Henan }\end{array}$} & I-NY-0214 & nd & nd & 0.02 & nd & nd & 0.65 & nd & 0.76 \\
\hline & I-NY-0221 & nd & nd & nd & nd & 0.02 & 0.27 & nd & 0.90 \\
\hline & $\begin{array}{l}\text { O-NY- } \\
0214\end{array}$ & nd & nd & nd & nd & nd & nd & nd & nd \\
\hline & $\begin{array}{l}\text { O-NY- } \\
0221\end{array}$ & nd & 0.11 & 0.02 & nd & nd & nd & nd & 0.12 \\
\hline \multirow{4}{*}{$\begin{array}{l}\text { Jiujiang, } \\
\text { Jiangxi }\end{array}$} & I-JJ-0214 & 1.8 & nd & 1.6 & 0.06 & nd & nd & nd & 10 \\
\hline & I-JJ-0221 & nd & nd & 0.53 & nd & nd & nd & nd & 3.4 \\
\hline & $\begin{array}{l}\text { O-JJ- } \\
0214\end{array}$ & 6.0 & 0.80 & 0.69 & nd & nd & nd & nd & 18 \\
\hline & $\begin{array}{l}\text { O-JJ- } \\
0221\end{array}$ & nd & nd & 0.29 & nd & nd & nd & nd & 1.5 \\
\hline \multirow[t]{4}{*}{ Hongkong } & I-HK-0214 & 11 & 1.5 & 0.15 & 0.11 & 1.2 & 1.1 & nd & 16 \\
\hline & I-HK-0221 & 8.4 & 1.5 & 0.49 & 0.10 & 0.10 & 0.88 & 0.34 & 12 \\
\hline & $\begin{array}{l}\text { O-HK- } \\
0214\end{array}$ & 14 & 6.0 & 1.6 & 0.08 & 0.65 & 2.6 & 1.6 & 29 \\
\hline & $\begin{array}{l}\text { O-HK- } \\
0221\end{array}$ & 5.5 & 1.1 & 0.17 & 0.12 & 0.08 & nd & 0.28 & 7.4 \\
\hline $\begin{array}{l}\text { Shijiazhuang, } \\
\text { Hebei }\end{array}$ & $\begin{array}{l}\text { I-SJZZ- } \\
0214\end{array}$ & 0.57 & 0.12 & 0.02 & nd & nd & nd & nd & 1.0 \\
\hline
\end{tabular}

nd: not detected

$\sum$ PFAA*: The sigma concentrations of 22 PFAA which could be detected in this study. 


\begin{tabular}{|c|c|c|c|c|c|c|c|c|c|}
\hline City & $\begin{array}{l}\text { Sample } \\
\text { label }\end{array}$ & PFBA & PFNA & PFDA & PFUnDA & PFBS & $\begin{array}{l}6: 2 \\
\text { FTSA }\end{array}$ & $\begin{array}{l}\text { HFPO- } \\
\text { DA }\end{array}$ & $\sum$ PFAA \\
\hline & $\begin{array}{l}\text { I-SJZ- } \\
0221\end{array}$ & nd & nd & nd & nd & nd & nd & 0.28 & 0.28 \\
\hline \multirow{2}{*}{$\begin{array}{l}\text { Sanya, } \\
\text { Hainan }\end{array}$} & I-SY-0214 & 2.5 & 0.10 & 0.05 & 0.09 & nd & nd & 3.3 & 6.2 \\
\hline & I-SY-0221 & 4.9 & 0.42 & 0.09 & 0.04 & 0.01 & 0.29 & 1.1 & 7.0 \\
\hline \multicolumn{10}{|c|}{ nd: not detected } \\
\hline \multicolumn{10}{|c|}{$\sum$ PFAA $^{\star}$ : The sigma concentrations of 22 PFAA which could be detected in this study. } \\
\hline
\end{tabular}

The composition of PFAAs in indoor dust in the present study showed different patterns from previous studies. Jian et al. (2017) reported that PFOA was the predominant compound in most European countries (Jian et al., 2017). This profile pattern was consistent with their precursor composition in indoor air, i.e., FTOHs and FOSA/Es were at high levels, and may have come from household products. Similarly, in Norway, PFOA was the main compound in home dust to which humans were exposed (Poothong et al., 2020). This phenomenon was also be found in home dust in Belgium, Italy, and Spain (Fang et al., 2019b). Conversely, in Irish households, PFBS had a higher detection frequency $(81 \%)$ and average concentration $(17 \mathrm{ng} / \mathrm{g})$ than other compounds (Harrad et al., 2019). In China, near a mega fluorochemical industrial park, the percentages of PFOA for $\sum_{12}$ PFAA were more than $60 \%$ in 2014. In another study monitoring the dust in Chinese households between 2015 and 2017, PFHxS concentrations were 4 to 40 times higher than those of other PFAA, which differed from both the fluorochemical industrial park and European countries, possibly due to the application of its precursor perfluorohexanesulfonyl fluoride (PFHxSF) (Ao et al., 2019). PFBA and Cl-6:2 PFESA were detected in dust from student dormitories and communal flats in Guangzhou China, but the contribution was lower than that of PFBS, which was the major compound (Zhang et al., 2020a).

For outdoors environments, studies have usually focused on the particles in air, and the concentrations and composition have reportedly been influenced by many factors, e.g., location, relative humidity and daily precipitation (Fang et al., 2019b). In the Canadian Arctic, from 2006 to 2015, the most frequently detected compound was PFBA, and the concentrations were higher than those of $\mathrm{C}_{8}$ homologues (Wong et al., 2018). In Beijing, China, PFBA and PFOA were found at comparable levels in the particle phase in Nov. 2013 (Wu et al., 2019). In Chengdu, China, PFOA contributed more than $80 \%$ of the $\sum_{12}$ PFAA concentrations indicating that legacy compounds were still the main contaminants in air particles collected from 2016 to 2017 (Fang et al., 2019b).

Spearman's rank correlation coefficients between PFBA and 6:2 FTSA $(r=0.807, p<0.01$ and between PFBA and HFPO-DA $(r=0.498, p<0.05)$ were positive and significant, suggesting the common sources of these alternatives for PFOA and PFOS. PFDA and PFNA were significantly related $(r=0.689, p<0.01)$. All were long-chained $(\mathrm{C}>8)$ PFAA which have stronger affinities to dust than short-chained compounds.

\subsection{Spatial comparison}


The distribution of $\sum$ PFAAs was showed in Fig. 2. Relatively high levels of $\sum$ PFAA were detected SC I. The highest concentration of $\sum$ PFAA was detected in Xinzhou on outdoor surface ( $\left.43 \mathrm{ng} / \mathrm{m}^{2}, 0-X Z-0214\right)$. Before $\mathrm{SC}$, the dust on the window glass had accumulated for one year, which was one reason for high concentration. Xinzhou is a city of Shanxi Province, which is famous for its coal industry. Air pollutions have been investigated in this province, and the dust was harmful with high heavy metal contents (Han et al., 2020, Su et al., 2020, Zhang et al., 2020b). PFAA concentration was not reported before. The high concentration revealed the organic pollution in this region. In Ordos, another city famous for textile manufacturing, the outdoor $\sum$ PFAA concentration was also at a high level of $28 \mathrm{ng} / \mathrm{m}^{2}$ (0-ORDS-0214). In Hong Kong, $\sum$ PFAA concentration of one sample collected on the outdoor surface in SC I was $29 \mathrm{ng} / \mathrm{m}^{2}$ (OHK-0214), higher than three other samples from the same city, and the window had last been cleaned 18 months previously. No intensive fluorine related industry distributed in this city. The airport might be one source due to the high concentrations of PFAA reported in airports in previous studies (Awad et al., 2011, Wang et al., 2016). In Sanmenxia, $\sum$ PFAA concentrations were comparably high at $33 \mathrm{ng} / \mathrm{m}^{2}$ (I-SMX-0214) indoors and $28 \mathrm{ng} / \mathrm{m}^{2}$ (O-SMX-0214) outdoors. PFAA transport from the air to the earth surface via atmospheric deposition (Galloway et al., 2020). Considering one important drinking water source is located in this city, PFAA in the dust should be concerned since the concentration in the drinking water source could be elevate due to the atmospheric deposition. Samples in Nanyang and Shijiazhuang presented low concentrations ( $\mathrm{nd}-1.0 \mathrm{ng} / \mathrm{m}^{2}$ ). Window cleaning had been conducted in both cities 7-10 days before SC I.

\subsection{Indoor/outdoor comparison}

The indoor and outdoor concentrations of $\sum$ PFAA were showed in Fig. 3a. In SC I, samples from 4 cities, i.e., Ordos, Xinzhou, Jiujiang, Hongkong, showed higher concentrations of $\sum$ PFAA on outdoor surfaces. In SC II, the concentrations in the same four cities were higher for indoor surfaces. During the Spring Festival, industrial activities slowed down, and indoor exposure from domestic sources was the major threat to human health. In Sanmenxia, samples collected on the same days presented comparable concentrations on both indoor and outdoor glass surfaces. Exchange of air between indoors and outdoors was weak in winter due to the low temperatures resulting in windows remaining closed. In Nanyang, indoor $\sum$ PFAA concentrations were at the same levels, although the samples were collected on different days, and concentrations were all slightly higher than that in outdoor samples. This indicated that the exposure risk in this city was mainly from indoor sources. In Tianjin and Handan, indoor concentrations of $\sum$ PFAA were higher outdoor in SC I, whereas the opposite was found in SC II.

For PFBA, the average concentration in SC I was $6.7 \mathrm{ng} / \mathrm{m}^{2}$ on indoor glass surfaces, which was lower than that outdoor $\left(10 \mathrm{ng} / \mathrm{m}^{2}\right)$ on the same day (8 cities, Shijiazhuang and Sanya were excluded due to the lack of outdoor samples). Higher concentrations were found on indoor surfaces in 5 cities, but not in Xinzhou, Jiujiang, and Hong Kong indicating intensive outdoor release in these three cities, probably from industries and airports (Table 3b). In SC II, the average concentrations on indoor and outdoor surfaces were 2.9 and $3.5 \mathrm{ng} / \mathrm{m}^{2}$, respectively. In Tianjin, concentration $\left(5.8 \mathrm{ng} / \mathrm{m}^{2}\right)$ outdoors was higher than indoors $\left(0.7 \mathrm{ng} / \mathrm{m}^{2}\right)$. For 6:2 FTSA, higher concentrations were detected on outdoor surfaces in Ordos (indoors: nd, outdoors: $16 \mathrm{ng} / \mathrm{m}^{2}$ ) and Xinzhou (indoors: $0.28 \mathrm{ng} / \mathrm{m}^{2}$, outdoors: $3.0 \mathrm{ng} / \mathrm{m}^{2}$ ) in SC I. Similarly, PFNA concentrations were higher outdoors in Xinzhou (indoors: $0.25 \mathrm{ng} / \mathrm{m}^{2}$, outdoors: $2.9 \mathrm{ng} / \mathrm{m}^{2}$ ) and Hongkong (indoors: 
$1.5 \mathrm{ng} / \mathrm{m}^{2}$, outdoors: $6.0 \mathrm{ng} / \mathrm{m}^{2}$ ) in SC I. For other long-chained PFAAs, i.e., PFDA, PFUnDA, and PFDoDA, no differences between indoor and outdoor samples were found.

\subsection{Comparison of the two sampling campaigns}

The comparison between the SC I and SC II was showed in Figure S1. Seven cities (Harbin, Ordos, Tianjin, Shijiazhuang, Nanyang, Hong Kong and Sanya) had comparable concentrations of $\sum$ PFAAs on indoor surfaces in SC I and SC II. The concentrations of $\sum$ PFAA were $1.3 \mathrm{ng} / \mathrm{m}^{2}\left(\right.$ I-ORDS-0214) and $1.3 \mathrm{ng} / \mathrm{m}^{2}($ IORDS-0221) for Ordos and $0.77 \mathrm{ng} / \mathrm{m}^{2}$ (I-NY-0214) and $0.90 \mathrm{ng} / \mathrm{m}^{2}$ (I-NY-0214) for Nanyang. The last cleaning was 7 days before $\mathrm{SC} \mathrm{I}$, but in additional 7 days of accumulation, concentrations did not change much in SC II. The concentrations of $\sum$ PFAAs were $16 \mathrm{ng} / \mathrm{m}^{2}$ (I-HK-0214) and $12 \mathrm{ng} / \mathrm{m}^{2}$ (I-HK-0221) for Hong Kong and $6.2 \mathrm{ng} / \mathrm{m}^{2}$ (I-SY-0214) and $7.0 \mathrm{ng} / \mathrm{m}^{2}$ (I-SY-0221) for Sanya, where the last cleaning before the SC I had been more than one year prior. In Harbin, Tianjin and Shijiazhuang, where the last cleaning before SC I had happened more than 7 days but less than one year prior, the concentrations of $\sum$ PFAA did not change significantly $(<25 \%)$ after 7 days of accumulation (i.e., from SC I to SC II). This implied that at least 7 days for equilibrium on horizontal glass in 7 cities mentioned above. Lower concentrations of ¿PFAA were found in SC II than SC I in the other 4 cities, i.e., Xinzhou (I-XZ-0214:11 ng/m², I-XZ0221:7.7 ng/m²), Handan (I-HD-0214:15 ng/m², I-HD-0221:3.4 ng/m²), Sanmenxia (I-SMX-0214:33 ng/m², ISMX-0221:6.2 ng/m²), and Jiujiang (I-JJ-0214:10 ng/ $\left.\mathrm{m}^{2}, \mathrm{I}-\mathrm{JJ}-0221: 3.4 \mathrm{ng} / \mathrm{m}^{2}\right)$, suggesting a longer equilibrium time than 7 days. For outdoor surfaces, concentrations were higher inSC II than inSC I in Tianjin (O-TJ-0214:2.7 ng/m², O-TJ-0221:13 ng/m²) and Handan (O-HD-0214:1.5 ng/m², 0-HD-0221:4.7 ng/m²), suggesting intensive outdoor sources. In Harbin and Nanyang, comparable concentrations were found in SC I and SC II, but the increasing trend was not negligible (O-HRB-0214:3.7 ng/m², O-HRB-0221:4.3 ng/m²; O-NY0214: nd, O-NY-0221:0.12 ng/m²). In other 5 cities, i.e., Ordos, Xinzhou, Sanmenxia, Jiujiang and Hong Kong, concentrations were lower in SC II thanSC I (seeing Figure S1). Indoor surfaces might be influenced by human activities which could result in particles falling off, while outdoor surfaces might be highly influenced by wet deposition (Wu et al., 2008). Unlike other semi-volatile organic compounds, PFAA are hydrophilic and mainly distributed in particle phase (Fang et al., 2018). PFAA could adsorb on glass materials, which is an unique behavior. Moreover, when degradation occurs on glass surfaces, concentrations of the compounds were not related to the content of organic carbon (Li et al., 2010). Future studies should be conducted to elucidate the behaviors of PFAA on the window glass surfaces.

\subsection{Toddlers' uptake estimations}

The uptake of PFAA via hand-to-mouth dust ingestion and dermal absorption were estimated by methods presented in previous studies (COPCC 2003, Liu et al., 2018, Poothong et al., 2019). Adults seldom touch window glass, but children may be attracted by the view outside when they are playing near windows and thus touch the glass. In this study, an average body weight of $12 \mathrm{~kg}$ for 2 year-old Chinese toddlers was applied when calculating intake. The exposure time was set as 1 hour/day according to the questionnaire. Older children may also touch windows, but the exposure values likely decrease due to decreasing exposure time and increasing body weight. The summary statistics of intakes of individual PFAA for which detection frequencies were higher than $50 \%$ and that of $\sum$ PFAA were showed in Table 2. The average estimated ingestion of $\sum$ PFAA (2.1 pg/kg body weight [bw]) via dust on window glass was higher than that for dermal 
absorption (both hands, $1.5 \mathrm{pg} / \mathrm{kg} \mathrm{bw}$ ). Ingestion intakes and dermal absorption of PFBA were higher than for other compounds. Estimated mean exposure values of 6:2 FTSA and HFPO-DA were all lower than $0.5 \mathrm{pg} / \mathrm{kg}$ bw. No safety thresholds were available for PFBA, 6:2 FTSA and HFPO-DA for toddlers, and more studies should be conducted in the future. Poothnog et al. (2019) calculated the exposure of adults to PFAS through hand-to-mouth contact and dermal absorption by measuring PFAS collected directly from hands using hand wipes (Poothong et al., 2019). PFOA and PFHpS were the two major compounds, with mean exposure values 2.0 and $6.2 \mathrm{pg} / \mathrm{kg} \mathrm{dw} \mathrm{d}$, respectively, for hand-to-mouth contact, and 1.2 and $3.7 \mathrm{pg} / \mathrm{kg} \mathrm{dw}$ $\mathrm{d}$, respectively, for dermal absorption, which differed from this study. When adults touch glass, the exposure to alternative compounds should be considered. The criteria developed by the European Food Safety Authority (EFSA) in 2008 was used to assess PFOA ( $1.5 \mu \mathrm{g} / \mathrm{kg} \mathrm{bw} \mathrm{d})$ and PFOS $(150 \mathrm{ng} / \mathrm{kg}$ bw d) daily exposure (EFSA 2008). Assuming the daily exposure time was 1 hour per day, the highest PFOA and PFOS intakes were $0.26 \mathrm{ng} / \mathrm{kg}$ bw d and $0.82 \mathrm{ng} / \mathrm{kg}$ bw d, values that are much lower than the risk criteria. For toddlers, the PFAA exposure scenarios might differ from those of adults due to their daily activity, living habits and low body weight. Moreover, besides windows, the other horizonal surfaces in the houses or flats should be considered, especially for toddlers between 1 and 2 year-old, since they would likely touch these surfaces when learning to walk.

Table 2

The estimated intake ( $\mathrm{pg} / \mathrm{kg}$ body weight) through hand-to-mouth dust ingestion and dermal absorption.

\begin{tabular}{|c|c|c|c|c|c|c|c|c|}
\hline & PFBA & PFNA & PFDA & PFUnDA & PFBS & 6:2 FTSA & HFPO-DA & $\sum$ PFAA* $^{*}$ \\
\hline & \multicolumn{8}{|c|}{ Ingestion intake } \\
\hline Max & 7.3 & 1.4 & 0.46 & 0.03 & 0.35 & 0.43 & 1.3 & 9.7 \\
\hline Min & 0.17 & 0.03 & 0.005 & 0.004 & 0.003 & 0.04 & 0.08 & 0.08 \\
\hline Mean & 1.4 & 0.26 & 0.07 & 0.01 & 0.04 & 0.14 & 0.48 & 2.1 \\
\hline \multirow[t]{2}{*}{ Median } & 0.87 & 0.10 & 0.04 & 0.01 & 0.01 & 0.09 & 0.28 & 1.9 \\
\hline & \multicolumn{8}{|c|}{ Dermal absorption } \\
\hline Max & 5.1 & 1.0 & 0.32 & 0.02 & 0.25 & 0.30 & 0.88 & 6.76 \\
\hline Min & 0.12 & 0.02 & 0.003 & 0.003 & 0.002 & 0.03 & 0.06 & 0.06 \\
\hline Mean & 0.94 & 0.18 & 0.05 & 0.01 & 0.03 & 0.10 & 0.33 & 1.5 \\
\hline Median & 0.61 & 0.07 & 0.03 & 0.01 & 0.01 & 0.06 & 0.19 & 1.3 \\
\hline
\end{tabular}

\subsection{Implications and limitations}

The dust on window glass has not been investigated frequently in previous studies. The conditions are unique due to the sunlight, heterogeneous medium and glass surface, which could influence the degradation 
of precursors and partitioning between gas and particle phases. The dust could be disturbed when opening and closing windows, thereby increasing the exposure risk for humans. Glass walls are widely used in apartments, offices, schools, hospitals, and laboratories to provide more sunlight and save energy. Ingestion and dermal intake should be concerned due to the fine particle size of dust and compounds found in dust and on glass. To avoid possible misevaluation, vertical surfaces in indoor and outdoor environments should not be ignored when collecting dust. In this study, sterile cotton balls were employed. They are easy to acquire and use and can be applied for monitoring .

There are several limitations in this study. Hotspot cities and background regions were not included, and the sampling intesity was low to provide a comprehensive understanding of distribution and human exposure. The detection limits were high for PFHpA and PFOA, which affected the discussion of sources. The cotton balls were not soaked in isopropyl alcohol or any other solvent; thus, PFAA absorbed on the glass may not be collected, which resulting in partial loss of the bulk film.

\section{Conclusion}

Twenty-two PFAAs were detected in dust collected from window glass from 11 Chinese cities. Three alternatives, PFBA, 6:2 FTSA and HFPO-DA were found in more than $50 \%$ samples suggesting the use of novel PFAA. PFBA was the predominant compound, indicating the shift to short-chained compound and its precursors. The two sampling campaigns were conducted before and after Chinese Spring Festival, in winter, when most people were off work and stayed at home, which may increase exposure time. Higher concentrations of PFAA were found on outdoor surfaces in 5 paired samples. In Tianjin and Handan, higher concentrations were found in outdoor dust after a further 7 days of accumulation (Feb. 14 to 21). Exposure via touching window glass touching may not be important for adults, but it should be considered for toddlers in view of their unique behaviors. Moreover, PFAA in dust from horizontal surfaces and impervious urban surfaces should be considered in future studies.

\section{Declarations}

\section{Acknowledgement}

This study was supported by the National Natural Science Foundation of China (NSFC 41977310). The authors would like to acknowledge the generous colleagues and students who collected the samples during 2018 Spring Festival.

\section{Ethical Approval}

The samples collected in this study were dust in households. No human or animal tissue, organs or cells were involved in the experiment. The sampling campaign used cotton balls which was not harmful to human subjects and the sampling processes did not use harmful solvent. The ethical committee approved the sampling campaign and the experiments.

\section{Consent to Participate}

Page 14/23 
The households in whose flats the samples were collected were all agree to participate in this study.

\section{Consent to Publish}

The participants and all the authors all agreed to publish the results in a public journal.

\section{Authors Contributions}

Zhen Zhao: Conceptualization, Methodology, Software, Writing - Review \& Editing, Data Curation

Linxia Yue: Data curation, Investigation

Hongqin Qiao: Writing- Original draft preparation, Data curation

Yinong Li: Data curation, Investigation

Xianghui Cheng: Data curation $₫$ Writing- Reviewing and Editing

Xia Hua: Visualization, Investigation, Data Curation

Tian Lin: Resources, Funding acquisition, Writing- Reviewing and Editing, Project administration

Qilu Li: Conceptualization, Investigation, Writing- Reviewing and Editing, Supervision

Hongwen Sun: Resources, Project administration

\section{Funding}

This study was financial supported by the National Natural Science Foundation of China (NSFC 41977310).

\section{Competing interests}

The authors declare that they have no known competing financial interests or personal relationships that could have appeared to influence the work reported in this paper.

\section{Availability of data and materials}

All data and materials were provided in supplementary material, and open to other researchers.

\section{References}

Ao, J.J., Yuan, T., Xia, H., Ma, Y.N., Shen, Z.M., Shi, R., Tian, Y., Zhang, J., Ding, W.J., Gao, L., Zhao, X.D. Yu, X.D., 2019. Characteristic and human exposure risk assessment of per- and polyfluoroalkyl substances: $A$ study based on indoor dust and drinking water in China. Environ Pollut. 254.

Doi:10.1016/j.envpol.2019.07.041.

Awad, E., Zhang, X., Bhavsar, S.P., Petro, S., Crozier, P.W., Reiner, E.J., Fletcher, R., Tittlemier, S.A. Braekevelt, E., 2011. Long-Term Environmental Fate of Perfluorinated Compounds after Accidental Release at Toronto 
Airport. Environ. Sci. Technol. 45, 8081-8089. Doi:10.1021/es2001985.

Bao, J., Liu, L., Wang, X., Jin, Y.-H. Dong, G.-H., 2017. Human exposure to perfluoroalkyl substances near a fluorochemical industrial park in China. Environmental science and pollution research international.

Doi:10.1007/s11356-017-8620-6.

Bao, J., Yu, W.J., Liu, Y., Wang, X., Jin, Y.H. Dong, G.H., 2019. Perfluoroalkyl substances in groundwater and home-produced vegetables and eggs around a fluorochemical industrial park in China. Ecotoxicol. Environ. Saf. 171, 199-205. Doi:10.1016/j.ecoenv.2018.12.086.

Besis, A., Botsaropoulou, E., Samara, C., Katsoyiannis, A., Hanssen, L. Huber, S., 2019. Perfluoroalkyl substances (PFASs) in air-conditioner filter dust of indoor microenvironments in Greece: Implications for exposure. Ecotoxicol. Environ. Saf. 183. Doi:10.1016/j.ecoenv.2019.109559.

Braun, J.M., 2017. Early-life exposure to EDCs: role in childhood obesity and neurodevelopment. Nat. Rev. Endocrinol. 13, 161-173. Doi:10.1038/nrendo.2016.186.

Cequier, E., lonas, A.C., Covaci, A., Maria Marce, R., Becher, G. Thomsen, C., 2014. Occurrence of a Broad Range of Legacy and Emerging Flame Retardants in Indoor Environments in Norway. Environ. Sci. Technol. 48, 6827-6835. Doi:10.1021/es500516u.

COPCC (2003). World Trade Center indoor environment assessment: Selecting contaminants of potential concern and setting healthbased benchmarks, Contaminants of Potential Concern Committee, World Trade Center Indoor Air Task Force Working Group.

D'Eon, J.C., Hurley, M.D., Wallington, T.J. Mabury, S.A., 2006. Atmospheric Chemistry of N-methyl Perfluorobutane Sulfonamidoethanol, $\mathrm{C}_{4} \mathrm{~F}_{9} \mathrm{SO}_{2} \mathrm{~N}\left(\mathrm{CH}_{3}\right) \mathrm{CH}_{2} \mathrm{CH}_{2} \mathrm{OH}$ :Kinetics and Mechanism of Reaction with OH. Environ. Sci. Technol. 40, 1862-1868. Doi:10.1021/es0520767.

Dauchy, X., Boiteux, V., Colin, A., Hemard, J., Bach, C., Rosin, C. Munoz, J.F., 2019. Deep seepage of per- and polyfluoroalkyl substances through the soil of a firefighter training site and subsequent groundwater contamination. Chemosphere. 214, 729-737. Doi:10.1016/j.chemosphere.2018.10.003.

de la Torre, A., Navarro, I., Sanz, P. Martinez, M.D., 2019. Occurrence and human exposure assessment of perfluorinated substances in house dust from three European countries. Sci. Total Environ. 685, 308-314. Doi:10.1016/j.scitotenv.2019.05.463.

Diamond, M.L., Gingrich, S.E., Fertuck, K., McCarry, B.E., Stern, G.A., Billeck, B., Grift, B., Brooker, D. Yager, T.D., 2000. Evidence for organic film on an impervious urban surface: Characterization and potential teratogenic effects. Environ. Sci. Technol. 34, 2900-2908. Doi:10.1021/es9906406.

Dinglasan, M.J.A., Ye, Y., Edwards, E.A. Mabury, S.A., 2004. Fluorotelomer alcohol biodegradation yields polyand perfluorinated acids. Environ. Sci. Technol. 38, 2857-2864. Doi:10.1021/es0350177.

EFSA (2008). Perfluorooctane sulfonate (PFOS), perfluorooctanoic acid (PFOA) and their salts. 
Egeghy, P.P. Lorber, M., 2011. An assessment of the exposure of Americans to perfluorooctane sulfonate: A comparison of estimated intake with values inferred from NHANES data. Journal of Exposure Science \& Environmental Epidemiology. 21, 150-168. Doi:10.1038/jes.2009.73.

Ellis, D.A., Martin, J.W., De Silva, A.O., Mabury, S.A., Hurley, M.D., Sulbaek Andersen, M.P. Wallington, T.J., 2004. Degradation of Fluorotelomer Alcohols: A Likely Atmospheric Source of Perfluorinated Carboxylic Acids. Environ. Sci. Technol. 38, 3316-3321. Doi:10.1021/es049860w.

Eriksson, U. Karrman, A., 2015. World-Wide Indoor Exposure to Polyfluoroalkyl Phosphate Esters (PAPs) and other PFASs in Household Dust. Environ. Sci. Technol. 49, 14503-14511. Doi:10.1021/acs.est.5b00679.

Fang, S.H., Zhu, H.X., Ye, Z.X., Yin, H.L. Sun, J., 2019a. Pollution Characteristics and Exposure Risk Assessment of Perfluoroalkyl Substances in Road Dust, Chengdu. Huan jing ke xue=Huanjing kexue. 40, 5265-5271. Doi:10.13227/j.hjkx.201906186.

Fang, S.H., Li, C., Zhu, L.Y., Yin, H.L., Yang, Y.C., Ye, Z.X. Cousins, I.T., 2019b. Spatiotemporal distribution and isomer profiles of perfluoroalkyl acids in airborne particulate matter in Chengdu City, China. Sci. Total Environ. 689, 1235-1243. Doi:10.1016/j.scitotenv.2019.06.498.

Fang, X., Wang, Q., Zhao, Z., Tang, J., Tian, C., Yao, Y., Yu, J. Sun, H., 2018. Distribution and dry deposition of alternative and legacy perfluoroalkyl and polyfluoroalkyl substances in the air above the Bohai and Yellow Seas, China. Atmospheric. Environ. 192, 128-135. Doi:10.1016/j.atmosenv.2018.08.052.

Feng, X.M., Ye, M.Q., Li, Y., Zhou, J., Sun, B.B., Zhu, Y.M. Zhu, L.Y., 2020. Potential sources and sediment-pore water partitioning behaviors of emerging per/polyfluoroalkyl substances in the South Yellow Sea. J. Hazard. Mater. 389. Doi:10.1016/j.jhazmat.2020.122124.

Field, J.A. Seow, J., 2017. Properties, occurrence, and fate of fluorotelomer sulfonates. Critical Reviews in Environmental Science and Technology. 47, 643-691. Doi:10.1080/10643389.2017.1326276.

Fleming, T.J. Ashley, J.T.F. (2013). Polycyclic Aromatic Hydrocarbon (PAH) Residues on Tobacco Smokers' Hands: Potential Vector for Exposure to Non-Smokers. Occurrence, Fate and Impact of Atmospheric Pollutants on Environmental and Human Health. McConnell, L.L., Dachs, J. Hapeman, C.J. 1149: 83-93.

Franko, J., Meade, B.J., Frasch, H.F., Barbero, A.M. Anderson, S.E., 2012. Dermal Penetration Potential of Perfluorooctanoic Acid (PFOA) in Human and Mouse Skin. Journal of Toxicology and Environmental HealthPart a-Current Issues. 75, 50-62. Doi:10.1080/15287394.2011.615108.

Galloway, J.E., Moreno, A.V.P., Lindstrom, A.B., Strynar, M.J., Newton, S., May, A.A. Weavers, L.K., 2020. Evidence of Air Dispersion: HFPO-DA and PFOA in Ohio and West Virginia Surface Water and Soil near a Fluoropolymer Production Facility. Environ. Sci. Technol. 54, 7175-7184. Doi:10.1021/acs.est.9b07384.

Gao, L., Liu, J., Bao, K., Chen, N. Meng, B., 2020. Multicompartment occurrence and partitioning of alternative and legacy per- and polyfluoroalkyl substances in an impacted river in China. Sci. Total Environ. 729, 138753. Doi:10.1016/j.scitotenv.2020.138753. 
Giesy, J.P. Kannan, K., 2002. Perfluorochemical surfactants in the environment. Environ. Sci. Technol. 36, 146A-152A. Doi:10.1021/es022253t.

Guo, M., Lyu, Y., Xu, T., Yao, B., Song, W., Li, M., Yang, X., Cheng, T. Li, X., 2018. Particle size distribution and respiratory deposition estimates of airborne perfluoroalkyl acids during the haze period in the megacity of Shanghai. Environ Pollut. 234, 9-19. Doi:10.1016/j.envpol.2017.10.128.

Hammel, S.C., Hoffman, K., Phillips, A.L., Levasseur, J.L., Lorenzo, A.M., Webster, T.F. Stapleton, H.M., 2020. Comparing the Use of Silicone Wristbands, Hand Wipes, And Dust to Evaluate Children's Exposure to Flame Retardants and Plasticizers. Environ. Sci. Technol. 54, 4484-4494. Doi:10.1021/acs.est.9b07909.

Han, L.J., Zhou, W.Q., Li, W.F. Qian, Y.G., 2020. China's Complex Urban Air Pollution: An Improved Understanding with Ground Operational Measurements. Integrated Environmental Assessment and Management. 16, 306-313. Doi:10.1002/ieam.4254.

Harrad, S., Wemken, N., Drage, D.S., Abdallah, M.A.E. Coggins, A.M., 2019. Perfluoroalkyl Substances in Drinking Water, Indoor Air and Dust from Ireland: Implications for Human Exposure. Environ. Sci. Technol.53, 13449-13457. Doi:10.1021/acs.est.9b04604.

Herzke, D., Olsson, E. Posner, S., 2012. Perfluoroalkyl and polyfluoroalkyl substances (PFASs) in consumer products in Norway - A pilot study. Chemosphere. 88, 980-987. Doi:10.1016/j.chemosphere.2012.03.035.

Heydebreck, F., Tang, J., Xie, Z. Ebinghaus, R., 2015. Alternative and Legacy Perfluoroalkyl Substances: Differences between European and Chinese River/Estuary Systems. Environ. Sci. Technol. 49, 8386-8395. Doi:10.1021/acs.est.5b01648.

Emissions of Per- and Polyfluoroalkyl Substances in a Textile Manufacturing Plant in China and Their Relevance for Workers' Exposure. Environ. Sci. Technol. 50, 10386-10396. Doi:10.1021/acs.est.6b03213.

Higgins, C.P. Luthy, R.G., 2006. Sorption of perfluorinated surfactants on sediments. Environ. Sci. Technol. 40, 7251-7256. Doi:10.1021/es061000n.

Jian, J.M., Guo, Y., Zeng, L.X., Liu, L.Y., Lu, X.W., Wang, F. Zeng, E.Y., 2017. Global distribution of perfluorochemicals (PFCs) in potential human exposure source-A review. Environ. Int. 108, 51-62. Doi:10.1016/j.envint.2017.07.024.

Jogsten, I.E., Nadal, M., van Bavel, B., Lindstrom, G. Domingo, J.L., 2012. Per- and polyfluorinated compounds (PFCs) in house dust and indoor air in Catalonia, Spain: Implications for human exposure. Environ. Int. 39, 172-180. Doi:10.1016/j.envint.2011.09.004.

Kutsuna, S., Nagaoka, Y., Takeuchi, K. Hori, H., 2006. TiO(2)-induced heterogeneous photodegradation of a fluorotelomer alcohol in air. Environ. Sci. Technol. 40, 6824-6829. Doi:10.1021/es060852k.

Li, J., Del Vento, S., Schuster, J., Zhang, G., Chakraborty, P., Kobara, Y. Jones, K.C., 2011. Perfluorinated Compounds in the Asian Atmosphere. Environ. Sci. Technol. 45, 7241-7248. Doi:10.1021/es201739t. 
Li, J., Lin, T., Pan, S.-H., Xu, Y., Liu, X., Zhang, C. Li, X.-D., 2010. Carbonaceous matter and PBDEs on indoor/outdoor glass window surfaces in Guangzhou and Hong Kong, South China. Atmospheric. Environ. 44, 3254-3260. Doi:10.1016/j.atmosenv.2010.05.057.

Lindstrom, A.B., Strynar, M.J. Libelo, E.L., 2011. Polyfluorinated Compounds: Past, Present, and Future. Environ. Sci. Technol. 45, 7954-7961. Doi:10.1021/es2011622.

Liu, X., Cao, Z., Yu, G., Wu, M., Li, X., Zhang, Y., Wang, B. Huang, J., 2018. Estimation of Exposure to Organic Flame Retardants via Hand Wipe, Surface Wipe, and Dust: Comparability of Different Assessment Strategies. Environ. Sci. Technol. 52, 9946-9953. Doi:10.1021/acs.est.8b02723.

NHC (2009). Reference Standard for Growth and Development of Children Under 7 Years Old in China. OECD (2018). Toward a new comprehensive global database of per- and polyfluoroalkyl substances (PFAS): summary report on updating the OECD 2007 list of per and polyfluoroalkyl Substances (PFASs).

Poothong, S., Padilla-Sanchez, J.A., Papadopoulou, E., Giovanoulis, G., Thomsen, C. Haug, L.S., 2019. Hand Wipes: A Useful Tool for Assessing Human Exposure to Poly- and Perfluoroalkyl Substances (PFASs) through Hand-to-Mouth and Dermal Contacts. Environ. Sci. Technol. 53, 1985-1993.

Doi:10.1021/acs.est.8b05303.

Poothong, S., Papadopoulou, E., Padilla-Sanchez, J.A., Thomsen, C. Haug, L.S., 2020. Multiple pathways of human exposure to poly- and perfluoroalkyl substances (PFASs): From external exposure to human blood. Environ. Int. 134. Doi:10.1016/j.envint.2019.105244.

Rappazzo, K.M., Coffman, E. Hines, E.P., 2017. Exposure to Perfluorinated Alkyl Substances and Health Outcomes in Children: A Systematic Review of the Epidemiologic Literature. Int. J. Environ. Res. Public Health. 14. Doi:10.3390/ijerph14070691.

Sorengard, M., Franke, V., Troger, R. Ahrens, L., 2020. Losses of poly- and perfluoroalkyl substances to syringe filter materials. J. Chromatogr. A. 1609. Doi:10.1016/j.chroma.2019.460430.

Stout, D.M. Leidy, R.B., 2000. A preliminary examination of the translocation of microencapsulated cyfluthrin following applications to the perimeter of residential dwellings. Journal of Environmental Science and Health Part B-Pesticides Food Contaminants and Agricultural Wastes. 35, 477-489.

Doi:10.1080/03601230009373284.

Su, H., Lu, Y., Wang, P., Shi, Y., Li, Q., Zhou, Y. Johnson, A.C., 2016. Perfluoroalkyl acids (PFAAs) in indoor and outdoor dusts around a mega fluorochemical industrial park in China: Implications for human exposure. Environ. Int. 94, 667-673. Doi:10.1016/j.envint.2016.07.002.

Su, X.B., Ding, R. Zhuang, X.G., 2020. Characteristics of Dust in Coal Mines in Central North China and Its Research Significance. Acs Omega. 5, 9233-9250. Doi:10.1021/acsomega.0c00078. 
Sun, Y., Zhang, Q., Wang, H. Wang, W., 2015. OH radical-initiated oxidation degradation and atmospheric lifetime of N-ethylperfluorobutyramide in the presence of 02/NOx. Chemosphere. 134, 241-249.

Doi:http://dx.doi.org/10.1016/j.

Taniyasu, S., Yamashita, N., Yamazaki, E., Petrick, G. Kannan, K., 2013. The environmental photolysis of perfluorooctanesulfonate, perfluorooctanoate, and related fluorochemicals. Chemosphere. 90, 1686-1692. Doi:http://dx.doi.org/10.1016/j.chemosphere.2012.09.065.

UNEP. "The new POPs under the Stockholm convention.", from http://www.pops.int/TheConvention/ThePOPs/TheNewPOPs/tabid/2511/Default.aspx.

Wang, X., Wang, P. Sun, W., 2011. Calculation Chart of Chinese Human Body Surface Area. Journal of Bethune Military Medical College. 9, 39-40.

Wang, Y., Vestergren, R., Shi, Y.L., Cao, D., Xu, L., Cai, Y.Q., Zhao, X.L. Wu, F.C., 2016. Identification, Tissue Distribution, and Bioaccumulation Potential of Cyclic Perfluorinated Sulfonic Acids Isomers in an Airport Impacted Ecosystem. Environ. Sci. Technol. 50, 10923-10932. Doi:10.1021/acs.est.6b01980.

Watkins, D.J., McClean, M.D., Fraser, A.J., Weinberg, J., Stapleton, H.M. Webster, T.F., 2013. Associations between PBDEs in office air, dust, and surface wipes. Environ. Int. 59, 124-132.

Doi:10.1016/j.envint.2013.06.001.

Wong, F., Shoeib, M., Katsoyiannis, A., Eckhardt, S., Stohl, A., Bohlin-Nizzetto, P., Li, H., Fellin, P., Su, Y.S. Hung, H., 2018. Assessing temporal trends and source regions of per- and polyfluoroalkyl substances (PFASs) in air under the Arctic Monitoring and Assessment Programme (AMAP). Atmospheric. Environ. 172, 65-73. Doi:10.1016/j.atmosenv.2017.10.028.

Wu, J., Jin, H., Li, L., Zhai, Z., Martin, J.W., Hu, J., Peng, L. Wu, P., 2019. Atmospheric perfluoroalkyl acid occurrence and isomer profiles in Beijing, China. Environ Pollut. 255. Doi:10.1016/j.envpol.2019.113129.

Wu, R.W., Harner, T. Diamond, M.L., 2008. Evolution rates and PCB content of surface films that develop on impervious urban surfaces. Atmospheric. Environ. 42, 6131-6143. Doi:10.1016/j.atmosenv.2008.01.066.

Young, C.J., Furdui, V.I., Franklin, J., Koerner, R.M., Muir, D.C.G. Mabury, S.A., 2007. Perfluorinated Acids in Arctic Snow: New Evidence for Atmospheric Formation. Environ. Sci. Technol. 41, 3455-3461.

Doi:10.1021/es0626234.

Yu, S., Liu, W., Xu, Y., Zhao, Y., Wang, P., Wang, X., Li, X., Cai, C., Liu, Y., Xiong, G., Tao, S. Liu, W., 2018 a. Characteristics of perfluoroalkyl acids in atmospheric PM10 from the coastal cities of the Bohai and Yellow Seas, Northern China. Environ Pollut. 243, 1894-1903. Doi:10.1016/j.envpol.2018.10.002.

Yu, S.Y., Liu, W.J., Xu, Y.S., Zhao, Y.Z., Wang, P., Wang, X., Li, X.Y., Cai, C.Y., Liu, Y., Xiong, G.N., Tao, S. Liu, W.X., 2018b. Characteristics of perfluoroalkyl acids in atmospheric PM10 from the coastal cities of the Bohai and Yellow Seas, Northern China. Environ Pollut. 243, 1894-1903. Doi:10.1016/j.envpol.2018.10.002. 
Yuan, B., Tay, J.H., Papadopoulou, E., Haug, L.S., Padilla-Sanchez, J.A. de Wit, C.A., 2020. Complex Mixtures of Chlorinated Paraffins Found in Hand Wipes of a Norwegian Cohort. Environ. Sci. Tech. Let. 7, 198-205. Doi:10.1021/acs.estlett.0c00090.

Zhang, B., He, Y., Huang, Y., Hong, D., Yao, Y., Wang, L., Sun, W., Yang, B., Huang, X., Song, S., Bai, X., Guo, Y., Zhang, T. Sun, H., 2020a. Novel and legacy poly- and perfluoroalkyl substances (PFASs) in indoor dust from urban, industrial, and e-waste dismantling areas: The emergence of PFAS alternatives in China. Environ Pollut (Barking, Essex : 1987). 263, 114461-114461. Doi:10.1016/j.envpol.2020.114461.

Zhang, X., Bai, X., Li, C.H., Li, T., Wang, R.H., Zhao, Z.H. Norback, D., 2020b. Elemental composition of ambient air particles in Taiyuan, China: evaluation of lifetime cancer and non-cancer risks. Human and Ecological Risk Assessment. 26, 1391-1406. Doi:10.1080/10807039.2019.1579048.

Zhao, Z., Cheng, X., Hua, X., Jiang, B., Tian, C., Tang, J., Li, Q., Sun, H., Lin, T., Liao, Y. Zhang, G., 2020. Emerging and legacy per- and polyfluoroalkyl substances in water, sediment, and air of the Bohai Sea and its surrounding rivers. Environ Pollut (Barking, Essex: 1987). 263, 114391-114391.

Doi:10.1016/j.envpol.2020.114391.

Zheng, G.M., Boor, B.E., Schreder, E. Salamova, A., 2020. Indoor exposure to per- and polyfluoroalkyl substances (PFAS) in the childcare environment. Environ Pollut. 258, 8. Doi:10.1016/j.envpol.2019.113714.

\section{Figures}

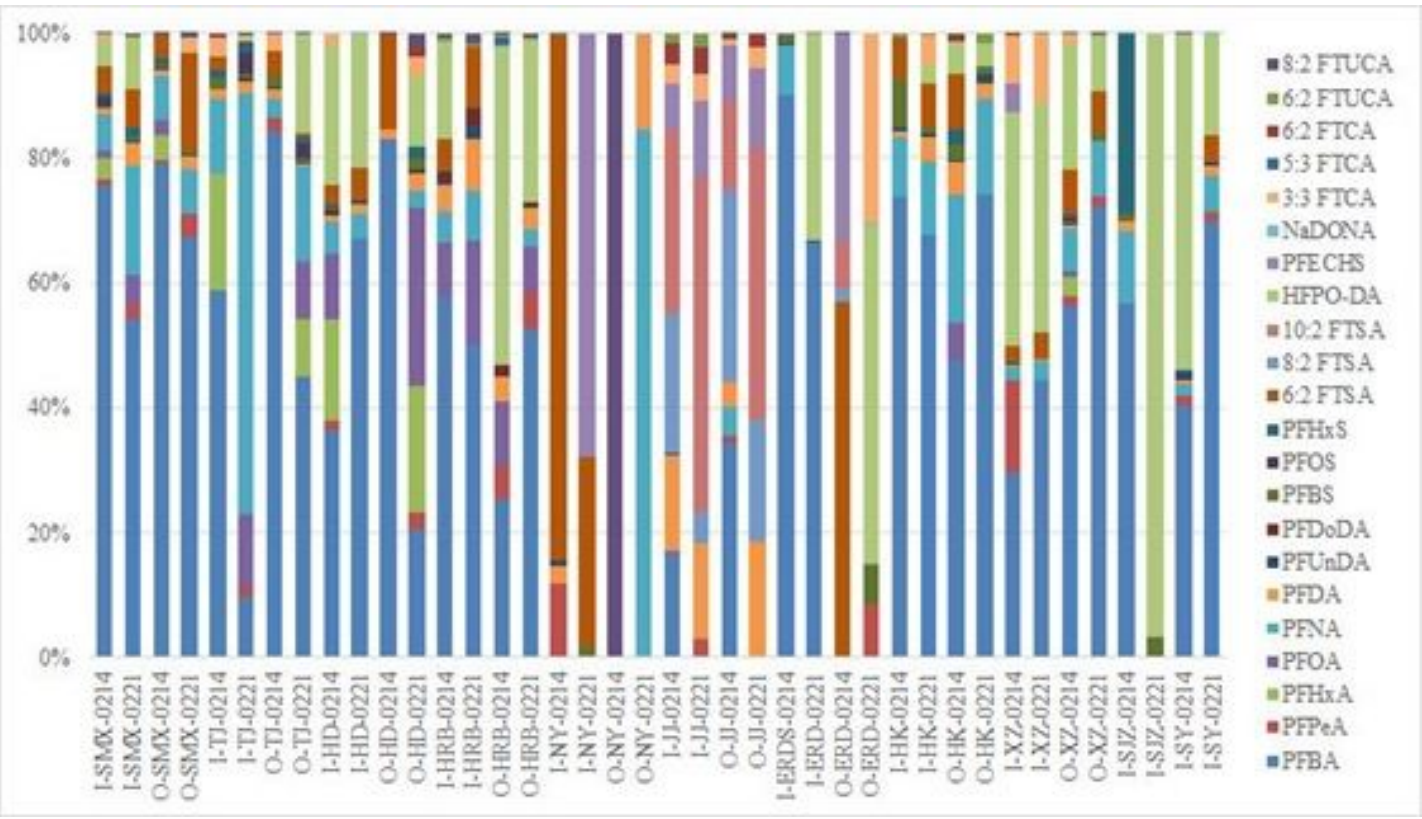

Figure 1

The composition of individual PFAA in the dust on the window glasses. 


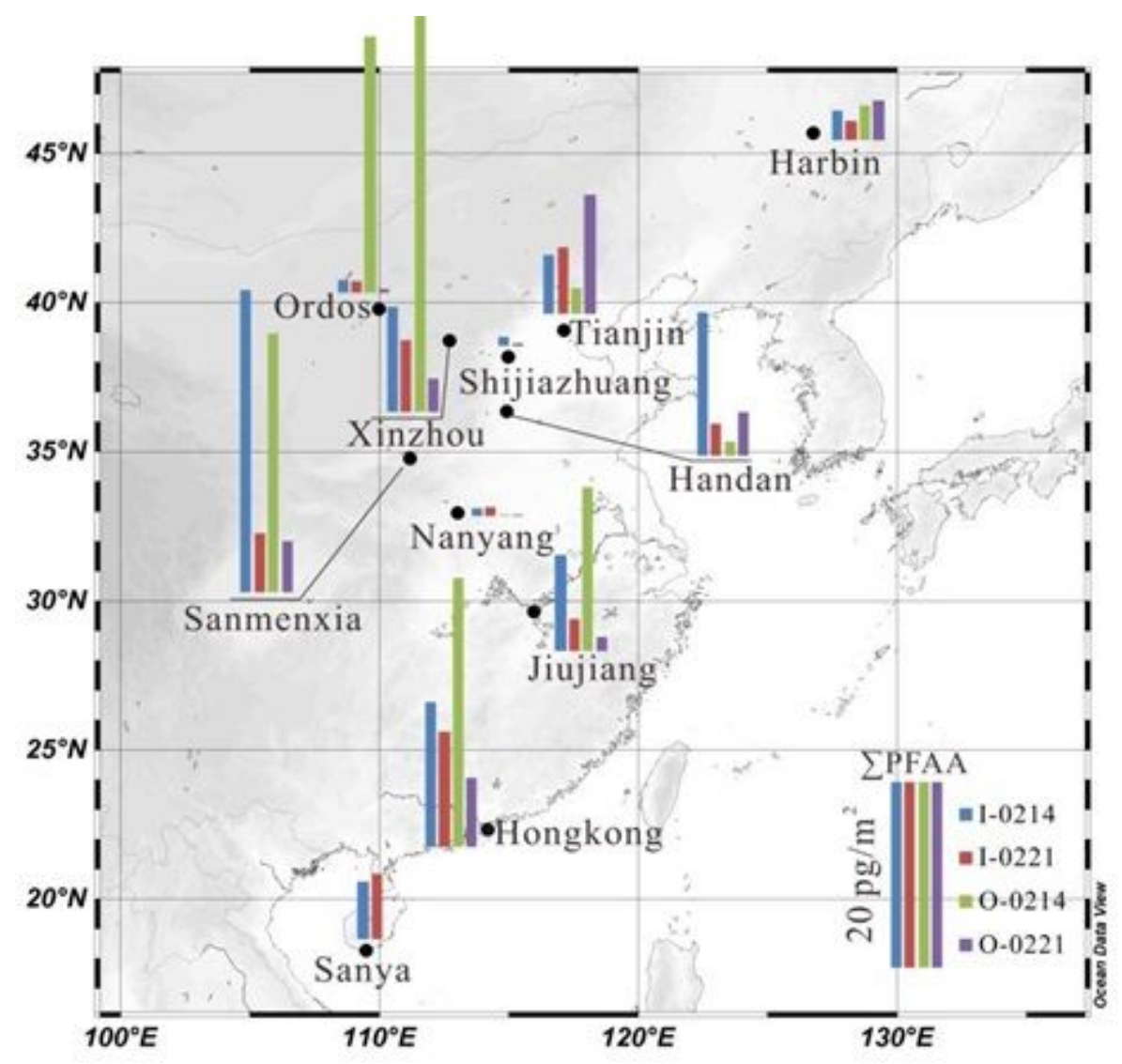

\section{Figure 2}

The distribution of $\sum$ PFAA in 11 cities in 2018. I-0214 represented the indoor dust collected on Feb.14. I0221 represented the indoor dust collected on Feb.21. 0-0214 represented the outdoor dust collected on Feb.14. 0-0221 represented the outdoor dust collected on Feb.21. Note: The designations employed and the presentation of the material on this map do not imply the expression of any opinion whatsoever on the part of Research Square concerning the legal status of any country, territory, city or area or of its authorities, or concerning the delimitation of its frontiers or boundaries. This map has been provided by the authors. 

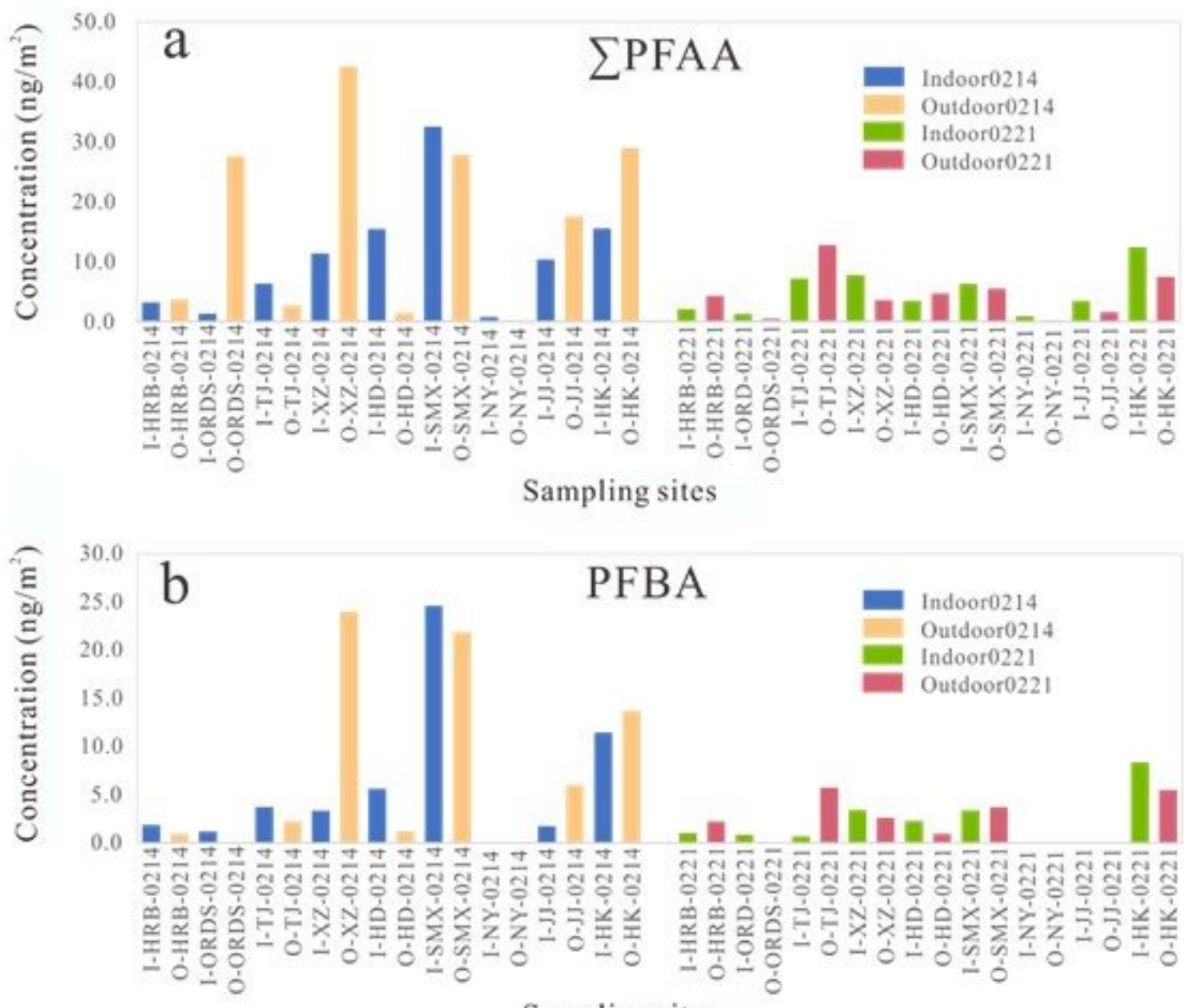

Sampling sites

\section{Figure 3}

The indoor and outdoor concentrations of $\sum$ PFAA (a) and PFBA (b) $(n g / m 2)$.

\section{Supplementary Files}

This is a list of supplementary files associated with this preprint. Click to download.

- SI20201231.docx 